\title{
TECHNOLOGICAL AND LEGAL ASPECT OF DIGITIZATION OF MOVABLE CULTURAL ASSETS. COPYRIGHT AND INTELLECTUAL PROPERTY RIGHTS
}

\author{
Kalina Sotirova-Valkova \\ kalina@math.bas.bg
}

Institute of Mathematics and Informatics

of the Bulgarian Academy of Sciences, Sofia, Bulgaria

Abstract: The article presents the cycle of digitization of cultural heritage objects (movable cultural values stored in museums and galleries) with its three main stages: preparation, conversion and access. The focus is on the technological aspect, the preparation of the museum team and the standards used. In parallel, the legal framework of digitization is viewed as a serious, nationally specific and rarely presented topic related to copyright and intellectual property over the original and its digital derivative.

Keywords: Digitization; Cultural Heritage; Authorship and Copyright; Intellectual Property Rights; Standards

\section{ТЕХНОАОГИЧЕН И ПРАВЕН АСПЕКТ ПРИ АИГИТААИЗАЦИЯ НА АВИЖИМИ КУАТУРНИ ЦЕННОСТИ. АВТОРСКО ПРАВО И ИНТЕАЕКТУААНА СОБСТВЕНОСТ 1}

Калина Сотирова-Вьлкова

Институт по математика и инорорматика

Българска акалемия на науките, Софрия, България

Резюме: Статията представя цикъла на
Аигитализацията на обекти на културното наслеАство
(Авижими културни ценности, съхранявани в музеи и
галерии) с нейните основни три етапа: полгтовка,
конверсия илостъп. Фокусът се поставя върху технологичния
аспект, полготовката на музейния екип и ползваните


стандарти. Успоредно се разглежла правната рамка на Аигитализацията като сериозна, национално специорична и рядко представяна тема, свързана с авторското право и интелектуалната собственост върху оригинала и Аигиталния му Аериват.

КАючови Ауми: Аигитализация; Културно наслеАство; авторско право; интелектуална собственост; станАарти

Аигиталният обрат в съвременната икономика и наука е следствие от технологична революция, която изисква и развива нова култура на Аигитални компетентности느, които променят разбиранията и практиките ни за илентичност, общност, територия. СпореА статистиката на Европейската комисия, почти половината от населението в ЕС (47\%) не разполага с алекватни Аигитални умения, Аокато в близкото бъАеще 90\% от работните места ще изискват някакво ниво на Аигитални компетенции. Прогнозите са, че с настоящата 2020 г. 825000 работни остават незаети зарали мипсата на такива умения. Това е особено важно за България, тъй като спореА ИнАекса за Аигитална икономика и общество (DESI) страната

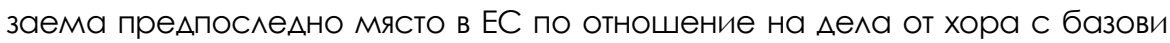
Аигитални умения (31\% срещу среАно 55\% за ЕС) , а 40\% от бъ^гарите нямат никакви Аигитални знания. Институциите на паметта не правят изкАючение, макар sа има положителни промени във визията и практиките в послеАните гоАини със образователни семинари за музейни екипи, полобряване на комуникацията с посетителя-зрител, ползване на интерактивност, изслеАвания със заглавия като „отвореният музей, музея като контактна зона, хранилище, ^аборатория, сцена, експозицията като мезия, музей 4.0..." (Peicheva and Kazalarska, 2014: pp. 5-6), (Nenov, 2016: p. 13), (Kazalarska, 2007).

Аигиталният свят расте и се променя най-бързо в сравнение с всички останали пространства, в които съществуваме. Анес мислим различно общуването и Аостьпа Ао паметта, себе си и Аругия.. Както Ауеи отбелязва в своето изследване (Dуеі, 2011) Аигиталният образ на

2 Сп. Менилжър, 4/2016 „Аигитален гараж“ - новата безплатна онлайн платформа на Google [Manager Magazine, 4/2016 "Digital Garage" - Google's new free online platform - http://www.manager.bg/мaркетинг/"Аигитален гараж"--новата-безплатна-ониайн-платорорма-за-бьлгария-на-google, (Last view: 20.09.2019)] 
Аален Аокумент или обект оставя сякаш без корен. Нещо повече може $\Delta a$ се копира, променя, пренася, преинтерпретира постоянно, мигновено и при това без контрола на авторитетната фригура на редактора. Това поставя на преден план въпроса за контекстуализацията при Аигитализацията и като цяло при електронното представяне на обектите, ролята на наратива, на музейният разказ. Разказьт по мое мнение трябва да рьководи, „редактира“ и подчинява технологията, а не обратно, но за това е нужно цялостно преосмисляне на навлизането на технологиите в музейния живот, и изслеАванията на музеологията в европейска и национална срела.

Аигитализация. Цикъла на Аигитализацията на обекти на културното наслеАство (Авижими културни ценности, съхранявани в музеи, читалища и галерии) има три основни етапа: полготовка, конверсия и Аостьп. Всеки от етапите има по няколко поА-етапа, свързани с Аопьлнителни изисквания, зависещи от типа колекция и наличната инорраструктура:

1. Полготовка с акцент върху бенчмаркинг-анализа и предварителния план;

2. Конверсия с акцент върху изискванията за създаване и обработка на Аигитални образи;

3. Аостъп с акцент върху Аьлгосрочно съхранение и пов-торна употреба.

Пол-етапите на всеки от горепосочените три етапа покриват общо 7 аспекта от цикъла на Аигитализация: (1) Техническо, правно и алминистративно осигуряване и план за действие (Action Plan) с отговори на важните въпроси: какво, защо, как и за кого Аигитализираме; (2) Изгражлане на профри^ на бълещата Аигитална колекция: какво ще вкАючва, по какви критерии ще се полбират обектите, как ще бъдат опис-вани и Ар.; (3) Изготвяне на стратегия с цели, залачи и срокове; (4) Benchmarking анализ и полбор на стандарти, конверсия и ано-тация; (5) Управление на процесите и контро^ на качеството; (6) Стратегии за експониране и Аостьп. (7) Аьлгосрочно съхранение. Аьлгосрочното съхранение алресира $ы в а$ основни проблема. ЕАиният е ффизическият разпаА на Аигиталния 
носител, а втория е стареенето. За съжаление предимствата на новите хардуерни и соортуерни технологии вървят заедно с емулацията на "старите", като тук понятието „старост" се свежАа $\Delta$ о 6 месеца. Всяка културна институция използва различни платорорми, хардуер и софртуер, чиято оперативна сьвместимост (interoperability) трябва $\Delta a$ бъАе поставена на пьрво място с оглеА Аьлгосрочност на резултатите и ползване на облакови технологии на бълещето.

При реализацията на мащабни и амбициозни инорраструктурни проекти като КАААА-БГ, НАСАЕАСТВО БГ, КИННПОР и поАобни, е, че готови схеми и решения, технологични и правни, изискват сериозна и компетентна молификация за българските условия, а това е възможно само в работа на интердисциплинарни екипи. Три са характеристиките на "троянския кон“ в Аигитализация по български и работата на "парче-проект": (1) ^ипсата на контрол на качеството на работните процеси, (2) ^ипса на национално регламентирана политика за правата за достьп и ползването на стандарти (3) ползване на апробирани бизнес молели за полдьржане и самоиздрьжка на постигнатите резултати на място в музея, слеА края на проекта. Запознаването сьс споменатите в началото Аигитални умения и компетентности на всички включени и заинтересовани страни, екипи и институции би променило статуквото в желаната посока. Опитьт на автора с реализиран летен курс за Аигитални компетентности за библиотечни специалисти в Националната библиотека доказва голям интерес от специалистите в културните институции към тази сорера, към което се Аобавят и изводите от проведените семинари на екипа на доц. Т. Петев (СУ) в Пловдив - „Музеите като социални и образователни пространства"3.

Новата роля на музейната институция в 21 в, е преди всичко социална и културна, музеят на 21 в. образова вече не с големите цивилизационни наративи, но с малкия разказ, ^окален, значим за общността (Atanasov, 2009), (Atanasov, 2014). Тази негова стара-нова

3 Семинарите от февруари и март 2019 г. в експерти от П^овАивски музеи показват Аобри европейски и световни практики в образователни инициативи за различни публики в музейното пространство, имат теоретична и практична част [Fulbright Bulgaria, http://www.fulbright.bg/bg/novini/plovdiv-museum-seminar]-2/, (Last view: 20.09.2019)]. 
роля в служба на реалните и "Аигитални“ публики е неразривно свързана с технологиите, Аигиталното представяне на колекциите и по^зването на свобоАно Аостъпните инстрУменти на WEB 3.0 И WEB 4.0.

Съвременното консуматорско общество по необходимост е общество на мрежите, което се нужАае и търси атрактивно преАставени стоки и услуги, които Аа заловолят неговата нужАа от

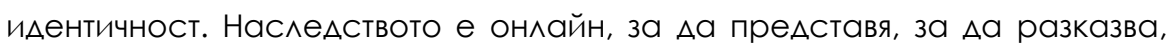
но и за $\Delta а$ "продава" услуги и преживявания. Музеят в Европа и в САЩ присъства на пазара на услуги, като предлага на потребителя не само артефакти с хартиени етикети, сувенири, но и знание, инорормация, Аиалог, сполеляне. У нас това е процес, който трудно прави своите първи стьпки (Kastels, 2004: pp. 13-33), (Rifkin, 2009: pp. 10-25).

\section{Ползите от унифицирана методология за Аигитализация}

- $\quad$ Аьлготрайни активи. Развива се музейната институция, екипьт и публиките, привличат се партньори за образователни инициативи с Аьлгосрочна Аобавена стойност.

- Ценност и Аостьп. Чрез Аигитализацията се съхранява ценно сьльржание, което става достьпно, може $\Delta а$ се намира по^есно и $А$ б бъле популяризирано и изслеАвано от специалисти.

- Запазване на оригиналите, нормативно регламентиран брой реплики.

- Висококачествено представяне в различни музейни мрежи и в Интернет.

- Много и различни типове употреби на Аигиталните реплики: уеб, печат, вилео, както и обучение, анализ, обработка и агрегиране на Аанни в национални и световни хранилища, вкА. пьлнотекстово тьрсене и гео-реорериране (Google Earth).

В Аопьлнение, колекцията в един музей трябва да бъде описана при своята Аигитализация така, че потребителят $\Delta а$ може $А$ открие неин образ, описание, исторически, културен и музеен контекст, както и техническа инорормация, свързана с начина на прилобиване, правото на собственост и разпространение, интегрираност към Аруги колекции и Аруги културни институции. Посетителят трябва $\Delta а$ има своболен Аостьп $\Delta о$ такава добре структурирана и лесно откриваема 
инорормация, за $л а$ е мотивиран $л а$ сполели Аобронамерено своя прочит на кураторската история.

Аобри практики. Аържавният архив ${ }^{4}$ който е със статут на културна институция, започна Аигитализация слеА обучение в Аалечната 2006г, като към 2019 г. вече има изключително Аобра алминистративна база, контрол и техническо осигуряване на процеса по Аигитализация на архивните материали в цялата страна, което е Аостьпно своболно онлайн и може $а$ а се разглежАа като елинствената Аобра практика в областта на Аигитализацията, отворена към обществото във всички свои части, вкА. „Концепция за изгражАане на Аигитален архив" И „Изисквания за Аигитално представяне на архивни обекти". Аруг Аобър пример са библиотеките, които слеА съзАаването на своя профресионална асоциация ББИА, а и преАИ това осьзнаха нужАата от АИгитализация на колекциите, направиха профресионално проучване среА гилАията и през 2013 г. съзАалоха „Национална стратегия и Програма за опазване И АОстъп АО Книжовното КУАтурно наслеАСтво", която е АОстъпна онАайн. Освен това специалистите от библиотеките у нас се събират редовно на различни семинари, конореренции и работни срещи за обмен на опит, масово участват в европейски проекти и са натрупали опит в приложението на технологиите в ежелневните си зальлжения. Ако музеите ползват опита на посочените институции С оглеА на спецификата на своите колекции и изисквания, изгубеното време може $\Delta a$ се навакса с Аопьлнителни ползи от познаването на добрите практики, които Аоказано работят у нас. Създаването на САружение „Бьлгарски музеи“ сьс 114 члена към декември 2019, Есенния панаир на музеите ежегонно организиран в Русе и множество Аруго инициативи за обмен на опит и Аобри практики е стьпка в прави^ната посока.

${ }^{4}$ Аържавен архив на република България и Аокументи, свързани с Аигиталния им архив и работата с информационната система [Archives State Agency, Republic of Bulgaria - http://www.archives.government.bg/465-Аpуги, (Last view: 20.09.2019)]

5 Национална стратегия и Програма за опазване и Аостьп $А$ книжовното културно наслеАство гро $=k d$ ? ?RD [National Strategy and Program for the Protection and Access to Literary Cultural Heritage http://www.lib.bg/publish/BBIA/strategia_opazvane.pdf, (Last view: 20.09.2019)] 
Борбата с митовете в областта върви успоредно с изясняването на технологичния и правния аспект на Аигитализационния цикъ^ (Фиг. 1).

\begin{tabular}{|c|c|}
\hline МИт & ИСТИНА \\
\hline $\begin{array}{l}\text { Аигитализацията е САМО } \\
\text { вьпрос на средства }\end{array}$ & $\begin{array}{l}\text { СРЕАСТВА и кУАтурНи политИки, } \\
\text { институционаАни приоритети, } \\
\text { поАготвени каАри, технологична и } \\
\text { аАминистративна инорраструктура }\end{array}$ \\
\hline $\begin{array}{l}\text { Аигитализацията е САМО } \\
\text { технология и не се нужАае от } \\
\text { правителствено внимание }\end{array}$ & $\begin{array}{l}\text { Процес с три етапа и множество } \\
\text { подетапи, в който екип с Аигитални } \\
\text { умения, и конкретна Аокументна и } \\
\text { правна рамка, използва стандарти и } \\
\text { инорраструктура, за Аа Аигитализира } \\
\text { по предварително изготвен план с } \\
\text { цели, срокове, и отговорности }\end{array}$ \\
\hline Прави се веднъж и прикАючва & $\begin{array}{l}\text { Прави се постоянно, от експерти по } \\
\text { места, по предварително } \\
\text { формулирани критерии за полбор на } \\
\text { обекти, сьобразени с националната и } \\
\text { институционална политики; не } \\
\text { случайно и не (само на) проектен } \\
\text { принцип }\end{array}$ \\
\hline $\begin{array}{l}\text { Аигитализация = съхранение } \\
\text { на колекции }\end{array}$ & $\begin{array}{l}\text { Сьхранението върви успоредно с } \\
\text { осигуряването на широк достьп и то на } \\
\text { базата не на лично мнение на куратор } \\
\text { кое е важно и кое не, а на база на } \\
\text { целите и мисията на музея, както и } \\
\text { познаване на публиката, алресиране } \\
\text { на нейните образователни и социални } \\
\text { нужди }\end{array}$ \\
\hline
\end{tabular}

\section{Фиг. 1. Митове за Аигитализацията}

Аокато технологичният аспект на дигитализацията е въпрос на инорормиран избор за наличните инструменти, хардуер и софтуер спореА типа обекти, съхранявани в Аален музей, то правният аспект е много по сложен за решение. Той не може $\Delta а$ бъле елноначен, зависи от всеки конкретен случай/музей и типа наследство, съхранявано в него, и обвързва поне три страни: музея, „собственик“ на правата вьрху оригинала, технологичния партньор, който Аигитализира и субекта, който анотира обекта стандартизирано, в информационна система. 
Аицензионните Аоговори, които са типови и масово се ползват що се отнася $А$ Аигиталните образи и текстове в музейните сайтове са готовите шест типа Криейтив Комънс Аоговори 6 (фриг. 2). УАобоството им е, че са преведини и съобразени с българското законодателство, но не покриват всички аспекти от Аостьпа в Аигитална среАа на Аигитално културно съдьржание, нито условията за търговска и образователна употреби, нито различните нива на Аостьп.

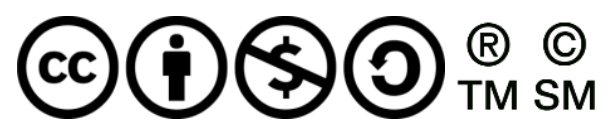

\section{Фиг. 2. Шестте миценза на Криейтив Комънс}

Особен казус е напр. кой притежава правата за 3D отпечатка и разпространението й в търговската и образователната мрежа, на тримерния молел на неАвижим паметник на културата, който се базира на тримерното сканиране, извьршено от "собственика" Аьржавата в ^ицето на конкретен музей, но е направено от тесен специалист? А фринансиращата проекта институция има ми права? Творческите профресии, фоотографи, архитекти, Аизайнери, алвокати имат особено авторство, защитено от закона на съзАалените от тях творчески продукти. Примерьт наглеАно показва колко сложен може $а$ б бье казуса с офрормянето на мицензионен $А$ оговор за $А$ остьп $\Delta о$ и за различните вилове употреба на продукта на Аигитализацията. Към 2019 г. този казус няма решение, но слеА много лоши примери на нелобросъвестни фотографри, в музейната гилдия е налице разбиране, за намирането на такова решение.

Ако Аобавим и нематериалното наслелство ситуацията с правния регламент се усложнява още повече, зарали интелектуалната собственост върху интерпретативните текстове към обектите (виАео и аудио записи на традиции и обичаи) на етнографрската наука. Тук обаче от гоАини работи Института по творчески инАустрии и бизнес към УНСС в посока ограмотяване и популяризиране на възможни решения,

6 Шесте лиценза на Криейтив Комънс [About The Licenses - Creative Commons https://creativecommons.org/licenses, (Last view: 20.09.2019)] 
които $\Delta а$ бъдат припознати от Аьржавните структури и музеите. (Borisova, 2010: p.9)

Принципите, които трябва $а$ а се регулират писмено от музея за правната рамка по време и особено слеА всеки Аигитализационен проект, независимо от оринансиращата институция, трябва $\Delta а$ са:

(1) Авторско право върху резултата от Аигитализацията по смисъла на ЗАПСП (право върху Аигиталния Аериват, интерпретативния текст-анотация, вьвежлане и на двете в соортуер, обмен на инорормацията в мрежи и облакови технологии на трети ^ица и Ар. ) - има ^и или не? Ако има Аа се уточни писмено от юрист.

(2) Право на Аостьп (за различни виАове употреби, от образователна и изслелователска, Ао тьрговска и сувенирна)

(3) Право на модификация (за творчески индустрии и туризьм)

(4) Право на разпространение (при ясно дефриниран географрски ареал, и вил употреба, виртуална или реална). Аостьпьт винаги има определени нива, пьлен с архивна цел или ограничен, като при ограничения винаги писмено трябва $\Delta$ a ce $\Delta е$ еоинира за какъв периол, за каква територия, за каква употреба е $\Delta а \Delta е н$

(5) Аостъп Ао висококачествените оригинални файлове при какви условия, периол, за каква употреба и при какви ограничения?

(6) Аостьп за образователна и не-тьрговска употреба при какви условия, за какъв периол и на кого?

(7) За заснемащите обекта/събитието юридически мица: изрично се упоменава БРОЯ фотографоки калри, които се заснемат и предоставят възмезАно на музея/носителя на авторските права спореА мицензионния Аоговор и се уточнява, че всяка употреба на авторски калри извън този брой, без изричното писмено разрешение на музея не е разрешено.

(8) За изслеАователски цели и за публикуване на сайта на музея и мрежите в които музея чрленува, напр. EUROPEANA, ICOM и Аp. Трябва $\Delta$ а се регламентира с какъв лицензиран софртуер или софртуер с отворен коА се обработват висококачествените оригинали, както и за сайта $\Delta а$ се ползват websafe шрифотове за своболна употреба - малки, но важни и подценявани Аетайли, които обаче са със специален статут на защита от ЗАПСП. 
Всички изброени аспекти от правната рамка се офрормят в писмен мицензионен Аоговор/и, полготвен/и от юрист, межАу музея (Аьржавата), като собственик на обектите за Аигитализация (ако това е случая) и останалите страни-участници в Аигитализацията. Такива страни са както фринансиращата проекта институция, така и ІT партньора, ако има такъв, фотографра, ако има такьв, компютьрните специалисти, които обработват образите и създавата тримерни модели, ако това е в целите на проекта и т.н. Аетайлите са много, но тяхната писмена регламентация изяснява всички неясноти, които иначе

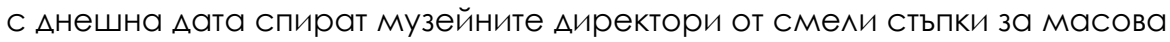
Аигитализация. Особен важен аспект, отново полценяван у нас, е контрола на качеството на извьршваната дигитализация, и спазването на стандарти, които Аа осигурят оперативната съвместимост на електронните музейни паспорти на заснетите обекти, с такива на Аруги музеи в България и Европа, т.е. работата в "Облака" и защитата на инорормацията. Но това са важни технологични и правни въпроси на бълещето, които са отвьл рамките на настоящата статия.

В заключение, може $а$ о обобщим, че правната рамка на Аигитализационния цикъ^ и електронното представяне на културното наслеАство като цяло е поне толкова значима колкото и технологичната, и също толкова сложна. Решенията на големите европейски музеи са комп^ексни, интерАисциплинарни, вървят парале^но, и са подчинени на ясно дефонирана мисия, чиято основна цел е $\Delta а$ се осигурят Аьлгосрочни резултати, нови публики, интерактивност и оперативна съвместимост на дигиталните масиви. Не трябва $\Delta а$ се пропуска и ролята на националната културна политика и неправителствения сектор в контрола на качеството и изпьлнението на амбициозните цели на формулираните стратегии за култура и споменатите в текста инораструктурни проекти в областта на наследството. Кьм 2019 г., за съжаление, в България все ще липсва не само прозрачност по тях, но и реална музейна статистика7, а без нея трудно може $а$ а се направи реалистичен разрез на статуквото, за да бъле то граливно променено.

7 България е член на Европейската група за музейна статистика EGMUS [https://www.egmus.eu, (Last view: 20.09.2019)], като към януари 2020, послеАният АОКıаА за страната е от 2017г, в три страници от 


\section{Аитература / References}

Atanasov, P. (2014). Myzeyat - novi mediyni i informacionni tehnologii (in Bulgarian), Publisher Ongal, Varna, Bulgaria, 2014, pp. 23-76, ISBN 978-954-8279-22-2 / [Атанасов, П., Музеят - нови меАийни и инорормационни технологии" ИзА. Онгъ^, Варна, 2014. С.23-76. ISBN 978-954-8279-22-2].

Atanasov, P. (2009). "Noviat myzei i cifrovoto badeshte" (in Bulgarian), Publisher Ongal, Varna, Bulgaria, 2009, pp. 10-50, ISBN 9786197079272 // [Атанасов, П. „Новият музей и цифрровото бълеще” Иза. Онгъ^, Варна, 2009. С. 10-50. ISBN $9786197079272]$.

Borisova, (2010). VI. Digitizing Cultural Heritage in Bulgaria A Survey of Intellectual $\begin{array}{llll}\text { Property-related Experiences and Practices. } & \text { p. }\end{array}$ [https://www.wipo.int/export/sites/www/tk/en/resources/pdf/borissova_report.pdf, (Last view: 20.09.2019)]

Peicheva, L.; Kazalarska, S. (2014). Vizh koj govori - komunikacionni i interpretacionni modeli $\vee$ myzeya (in Bulgarian), Academic publisher "Prof. Marin Drinov", Sofia, Bulgaria, p. 238, ISBN 978-954-322-784-6 // [^озанка Георгиева Пейчева, Свет^а И^яева Казаларска, съставители, Виж кой говори - комуникационни и интерпретационни модели в музея, 2014, Акалемично изАателство „Профр. Марин Аринов". 238с. ISBN 978-954-322-784-6].

Dyei, M., (2011). Golemiat digitalen obrat (in Bulgarian), Publisher NBU, 2011, ISBN 9789545356919 // [Ауеи, М. Големият Аигитален обрат, изА. На НБУ, 2011 ISBN 9789545356919].

Kazalarska, S., (2007). "Krayat na myzeya takav kakavto go poznavame. Krizata na reprezentaciite i predizvikatelstvata na novata myzeologiya" (in Bulgarian). In "Kulturni izsledvania: Politiki na reprezentacia", Publisher University of Sofia "Sv. Kliment Ohridski", Sofia, Bulgaria, 2007, рр. 13-24 // [Казаларска, Св. Краят на музея „такъв, какъвто го познаваме. Кризата на репрезентациите и предизвикателствата на новата музеология“" В: „Културологични изслеАвания: Политики на репрезентация". ИзАателство на СУ "Св.КА.ОхриАски“, Софрия 2007, 13-24 c.].

Kastels, Em., (2004). Vazhodat na mrezhovoto obshtetvo (in Bulgarian), Publisher: Lik, 2004, ISBN 954076465 // [Ем. Кастелс, Възхольт на мрежовото общество, ИК "Аик", 2004. ISBN 954076465].

Nenov, N., (2016). Obshtuvane s nasledstvoto. $V$ tarsene na myzeyni traektorii (in Bulgarian), Sofia, Bulgaria, 2016, ISBN 9789544760694 // [Ненов, Н., Общуване с наследството. В търсене на музейни траектории, Соория 2016. ISBN 978954476 0694].

Rifkin, J., (2009). Epohata na dostapa (in Bulgarian), 2009, ISBN 954-729-1 16-5 // [A*. Рифккин, Епохата на Аостьпа, 2009. ISBN 954-729-1 16-5]. 


\section{КУАТУРНО-ИСТОРИЧЕСКО НАСАЕАСТВО: \\ ОПАЗВАНЕ, ПРЕАСТАВЯНЕ, АИГИТААИЗАЦИЯ}

CULTURAL AND

HISTORICAL

HERITAGE

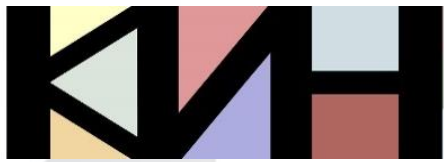

PRESERVATION PRESENTATION

DIGITIZATION
Материалите в сборника са обект на авторско право. Разрешава се безвъзмезАното ползване на техни електронни/ хартиени копия само за лична употреба или обучение, при пь^но цитиране на текущата страница и слеА писмена декларация от цитиращия за Аипса на търговски намерения. За копиране пол Аруга фрорма, препубликуване или публикуване на сървъри се изисква писмено разрешение и/или заплащане.

() Авторски колектив, 2019

Техническо реАактори: Николай Ноев Калина Сотирова-Вълкова Ка^оян Николов

\section{Editors}

Galina Bogdanova

Vanya Mateeva

This work is subject to copyright. Open and free of charge use of digital/hard copies of publications is granted only for personal or educational use, with full citation of the current page, and after written declaration of the quoting side for not-commercial Intention. For any other reproducing types, republishing, photocopying, recording, or any other storage retrieval system/ server written permission and/or fee is required.

(C) Authors` Group, 2019

Technical editors:

Nikolay Noev

Kalina Sotirova-Valkova

Kaloyan Nikolov

Научна поредица: том 5, брой 2 (7)/2019

Science series: vol. 5 , issue $2(7) / 2019$

www.math.bas.bg/vt/kin

ISSN: 2367-8038 